\title{
Telecommunications in healthcare: state, problems and prospects of development
}

\author{
Alla. Oshkordina*, and Felix Badaev \\ Ural State University of Economics, 620144 Yekaterinburg, Russia
}

\begin{abstract}
The authors of the article consider the features and problems of the introduction and implementation of telecommunications technologies in healthcare as one of the effective tools for improving the quality and accessibility of medical care to the population of Russia. The article systematizes and summarizes the information and theoretical material on the state and level of implementation of telecommunications technologies in the world practice. The authors present the results of the analysis of changes in the dynamics of telecommunications technologies used on the basis of a medical institution in the Sverdlovsk region. The main directions and prospects for the development of information technologies in medical organizations in the context of the prevention of coronovirus infection are determined. The authors draw a conclusion about the increase in the level of personification of the therapeutic and diagnostic process in modern healthcare, both on the part of the patient and on the part of the medical organization.
\end{abstract}

\section{Introduction}

In the world practice, over the past decade, more than 70 projects in the field of information and communication technologies in healthcare have been successfully developed and implemented in the economically developed countries of Europe, aimed at developing the e-health concept. The main goal of the implemented projects is the development and dissemination of information technologies in the activities of healthcare organizations around the world, focused on the registration and formalization of medical data, their preparation for the transfer and reception of a large volume of information and analytical material[1]. The indisputable advantages of the conceptual approach of e-health are the "erasing" of space-time boundaries in the field of health care and the increase in the speed of information processing with the help of modern technologies[2]. At the same time, it is necessary to note the existing shortcomings and problems that require immediate solution in the near future and involve the following issues:: imperfection and contradictions in the regulatory and legal regulation of the implementation of information methods and telecommunications; lack of skills and competencies of administrative, managerial and medical personnel of medical organizations; insufficient awareness of patients about the advantages and disadvantages of the introduction of telecommunications technologies; security of identification processes both on the part of medical personnel and on the part of

*Corresponding author: al2111la@yandex.ru 
the client; protection of the confidentiality of the information base of the client; creation of a legal framework and creation of mechanisms for its settlement both on the part of the medical organization and on the part of the patient.

The purpose of the study is to identify the main problems and directions in the development of information technologies and communications as a factor in improving the socio-economic efficiency of health organizations.

For the comprehensive implementation of information technologies in medical organizations and the organization of electronic services for citizens in the field of health care, in October 2016, the priority project "Improving the processes of organizing medical care through the introduction of information technologies" ("E-health") was approved at the meeting of the Presidential Council under the President of the Russian Federation for Strategic Development and Priority Projects. According to E. L. Boyko, the implementation of the priority project "E-health" will allow completing the tasks started in 2011 health informatization programs and will become the basis for the introduction of intelligent information systems and the latest technologies in practical health care [3].

Thus, the development, implementation and realization of information and telecommunications technologies in practical healthcare is of particular relevance today in order to improve medical, social, technological and economic efficiency. In addition, the introduction of telecommunications technologies in remote areas of Russia will increase the degree of timeliness and availability of high-quality medical care.

\section{Materials and methods}

The materials and research base were statistical, accounting, reporting and information sources of the activities of healthcare organizations in Russia and the Sverdlovsk region. The materials of scientific research of domestic and foreign scientists in the field of development, implementation and development of telecommunications technologies in healthcare are used. Methods of grouping, detailing, synthesis, historical and logical method of research, as well as methods of economic analysis were used in the processing and systematization of information and analytical material.

\section{Results and discussion}

Informatization of organizational, managerial and production processes has covered all spheres of economic life of modern enterprises in all sectors of the national economy. The introduction of information technologies in healthcare is observed almost from the first steps of the spread of information technologies in the world practice. Many foreign and domestic scientists in the field of informatization of production processes associate the evolution of the development and transformation of information technologies directly with the development of national health systems. Thus, information technologies began to be implemented on a large scale in the activities of medical organizations since the mid-70s of the last century, covering almost all areas of economic, managerial, medical and scientific activities of health organizations [4]. In Russian healthcare, information technologies have found practical application only since the beginning of the 90s of the last century, and they began to be introduced and used everywhere only in the early 2000s. Nevertheless, today it is difficult to imagine the functioning and management of a medical organization without the help of telecommunications tools in the conditions of rapidly changing factors of the external and internal environment and solving multi-format tasks. In addition, information technologies can be considered on the basis of three aspects of functionally solved tasks: 1) management of a medical organization, including organization, planning, control and 
accounting, as well as rational allocation and use of economic resources; 2) organization of medical activities, including the maintenance of electronic patient records, a set of medical tools for the treatment and diagnostic process, services for electronic patient records to the doctor, as well as improving the level of knowledge and exchange of experience of medical personnel, etc.; 3) e-health, consultations of specialists. In other words, these areas are focused: the first is aimed at the management of financial and production activities of a medical organization; the second is aimed at selecting effective medical tools for the treatment and diagnostic process, as well as at exceeding the quality of medical care; the third is aimed at creating mobile applications for patients.

The system of automated document management, the so-called "Medical Information System" (MIS), the main purpose of which is to integrate all areas and directions of financial and economic, administrative and managerial, research and professional medical activities, is the most widespread in the organizations and healthcare institutions of the Russian Federation. Thus, information technologies in health care have become quite firmly embedded in the daily activities of not only medical organizations, but also in the life of every person who uses mobile applications. Thus, the Unified State Information System in the field of Health Care in the Russian Federation combines all the information and analytical material of each medical institution that provides medical care in the country into a single database, which makes it possible to unify medical documentation for each patient. In 2017, a project was implemented to create a personal account "My Health" on the portal of public services, which, in the context of prevention and control of coronovirus infection, as well as other infectious and socially significant diseases, is an effective tool for monitoring the level of morbidity, as well as the level of prevention, vaccination and other measures.

According the world practice, telecommunications technologies have been used since the late 60 s-early 70 s of the last century, which were used not only to improve the efficiency of the medical and diagnostic process, but also for the rational use of all available economic resources. At the same time, the emergence and development of Internet technologies marked a new vector of development of tele-communication technologies in medicine and healthcare - telemedicine or telemedicine technologies. Telemedicine is not a new phenomenon in healthcare, it traces its history back to the middle of the XIX century [5]. At present, there are many approaches to the definition of the conceptual and terminological apparatus of this concept. Nevertheless, all the formulations reflect the availability of possible and appropriate directions of information and telecommunications technologies in the field of medical activity and improving the quality and accessibility of medical care to the population. In addition, over the past decade, another direction has been formed within the framework of telecommunications technologies - mobile healthcare (in the world practice of mHealth), focused on the use of individual technical electronic devices and gadgets by patients. Many domestic and foreign scientists consider this direction the main patient-oriented tool in the field of monitoring, accumulation and exchange of medical information for the current state of health of an individual patient.

In February 2016, the European Commission established a working group to develop rules for the examination of medical mobile applications and devices. In May 2016, a second draft of the rules appeared, establishing the criteria for their quality, safety, reliability and effectiveness [6].

Mobile healthcare (mHealth, mobile health) is a branch of telemedicine that provides medical care and controls a healthy lifestyle of a person using wireless telecommunications technologies and mobile devices. mHealth is a technological, medical and social "silent revolution" that is already taking place, which sooner or later will significantly affect the entire healthcare system as a whole. The era of "four-P" medicine (Predictive, Preventive, 
Personalized, involving the personal participation or involvement of the Patient), foreshadowed by many, will be based on mobile medicine and will become impossible without close cooperation between the patient and the doctor through technological solutions [7].

A joint study by the Economist Intelligence Unit and PWC in 2014 showed [8] that the main motivations for using mobile healthcare are to simplify access to healthcare $(46 \%)$, reduce healthcare costs $(43 \%)$, increase the number of opportunities to monitor one's own health $(32 \%)$, obtain previously inaccessible medical information $(28 \%)$, and improve the quality of health care $(25 \%)$. The expected turning point has already occurred in most countries: everyone understands that medicine can benefit from the development of information technology. The expansion of technological medical services has already begun, and their distribution is supported by corporations (for example, by insuring employees), and by patients themselves (for example, by purchasing a subscription for remote support of the pregnant). The transition to a health care model that can use the capabilities of mobile health (mHealth) is supported by e-health implemented at the regional level (the commonly used term is eHealth). Telemedicine, electronic medical records, online recording services - much of this is already familiar not only to the head of the clinic, but also to the doctors.

According to analysts at Research2Guidance, the mobile health industry will grow to almost $\$ 26$ billion by 2018. [9] In 2000, the United Nations and WHO estimated [10] that the world's population aged 60 and over was 600 million. This is almost three times more than in 1950. It is projected to reach a billion people by 2025, almost doubling in 25 years. According to Kubrik A. Yu. in the current socio-economic conditions of healthcare development, the only way to maintain good results in such conditions is to use integrated systems and care using mobile solutions [11]. Currently, the mobile application "Health" has been implemented for owners of electronic means of communication on the Android and iPhone platforms, which allows you to receive round-the-clock advice from medical personnel on issues of concern about changes in health conditions.

Thus, telecommunications technologies are firmly established in all sectors of the national economy, including health care, covering all areas of financial and economic, medical and research activities of medical institutions. In addition, modern telecommunications technologies make it possible to personalize the medical and diagnostic process with the ability to track changes in the patient's condition around the clock, while forming a clear statistical base for the effectiveness of medical appointments, which increases the quality and accessibility of medical care to the population, including the population in remote regions and localities, which Russia is very rich in.

The Sverdlovsk region is one of the largest industrially developed regions of the Russian Federation (about 4,000 industrial enterprises operate on the territory of the region, which aggravates the environmental and sanitary-epidemiological situation). The specific features of the territory are its rather large length, low population density, the inaccessibility of many localities and municipalities, as well as the underdeveloped transport and social infrastructure. The population of the Sverdlovsk region in recent years varies at the level of 4,300 thousand inhabitants. The largest city in the region, Yekaterinburg, is home to about 35-40 percent of the total population of the region [12].

One of the leading and largest clinics in the Urals and the Sverdlovsk region today is the Regional Clinical Hospital No. 1. This oldest medical institution in the Urals has more than 200 years of history and has a significant impact on the development of medical science and technology, as well as on the development and implementation of innovative technologies and methods of the medical and diagnostic process in the Sverdlovsk region. Based on the processing of the accounting and reporting documentation of the medical 
institution, the data on the dynamics of changes in the number of teleconsultations of the polyclinic department of the hospital, presented in Table 1, are analyzed.

Table 1. The number of teleconsultations of the polyclinic department of the Regional Clinical Hospital No. 1 of the Sverdlovsk region

\begin{tabular}{|l|l|l|l|l|l|}
\hline $\begin{array}{c}\text { Administrative territories of } \\
\text { the Sverdlovsk Region }\end{array}$ & $\mathbf{2 0 1 6}$ & $\mathbf{2 0 1 7}$ & $\mathbf{2 0 1 8}$ & $\mathbf{2 0 1 9}$ & $\mathbf{2 0 2 0}$ \\
\hline Eastern & 1176 & 1500 & 1637 & 1731 & 2642 \\
\hline South & 854 & 563 & 856 & 978 & 1546 \\
\hline Mining & 727 & 845 & 958 & 1004 & 1348 \\
\hline Western & 901 & 1115 & 1544 & 1635 & 2288 \\
\hline Northern & 994 & 1431 & 1482 & 1527 & 1836 \\
\hline Central & 116 & 115 & 162 & 189 & 33 \\
\hline Total for the Sverdlovsk region & 4768 & 5569 & 6639 & 7064 & 9663 \\
\hline
\end{tabular}

The data in Table 1 clearly indicate an annual planned increase in the number of teleconsultations in the context of the administrative districts of the Sverdlovsk region by an average of $7-16 \%$ in the period from 2016 to 2019, which underlines the growing popularity of the introduction and use of telecommunications technologies in medical practice both on the part of the patient and on the part of the medical institution. Attention is drawn to 2020 - the year of the fight against coronavirus infection, in which the increase in the number of teleconsultations increased by $36 \%$ compared to the previous 2019. and more than twice as high as the level of the indicator in 2016, which once again proves in favor of the development of telecommunications in healthcare. In addition, some variation in the number of teleconsultations in the administrative districts is due to the uneven distribution of the population in terms of density and the number of attached population of the Sverdlovsk region. The Central Administrative District includes such a large metropolis as the city of Yekaterinburg, where the service of the population is mainly attached to other medical and preventive institutions and organizations. This fact affects the low level of statistical indicators on the number of telecommunications technologies used.

Table 2. Structure of teleconsultations on specialization of rendering medical care to the population of the Sverdlovsk region

\begin{tabular}{|l|l|l|l|l|}
\hline \multirow{2}{*}{ Specialization } & \multicolumn{2}{c|}{ 2016 } & \multicolumn{2}{c|}{ 2020 } \\
\cline { 2 - 5 } & \multicolumn{1}{|c|}{$\begin{array}{c}\text { Number of } \\
\text { teleconsultations }\end{array}$} & $\begin{array}{l}\text { percentage, } \\
\text { \% }\end{array}$ & $\begin{array}{l}\text { Number of } \\
\text { teconsultations }\end{array}$ & $\begin{array}{c}\text { percentage, } \\
\text { \% }\end{array}$ \\
\hline Obstetrics and gynecology & 80 & 1,7 & 413 & 4,3 \\
\hline Allergology & 616 & 12,9 & 281 & 2,9 \\
\hline Gastroenterology & 219 & 4,6 & 350 & 3,6 \\
\hline Hematology & 1387 & 29,1 & 2332 & 24,1 \\
\hline Cardiology & 292 & 6,1 & 592 & 6,1 \\
\hline Coloproctology & 15 & 0,3 & 29 & 0,3 \\
\hline Neurology & 393 & 8,2 & 753 & 7,8 \\
\hline Neurosurgery & 13 & 0,3 & 4 & 0,0 \\
\hline Nephrology & 66 & 1,4 & 269 & 2,8 \\
\hline Ophthalmology & 26 & 0,6 & 1136 & 11,8 \\
\hline Pulmonology & 149 & 3,1 & 284 & 2,9 \\
\hline Rheumatology & 210 & 4,4 & 746 & 7,7 \\
\hline Cardiovascular Surgery & 0 & 0 & 158 & 1,6 \\
\hline $\begin{array}{l}\text { Traumatology and } \\
\text { orthopedics }\end{array}$ & 18 & 0,4 & 16 & 0,2 \\
\hline Urology & 548 & 11,5 & 394 & 4,1 \\
\hline Surgery & 54 & 1,1 & 54 & 0,6 \\
\hline Endocrinology & 682 & 14,3 & 1852 & 19,2 \\
\hline TOTAL & 4768 & 100 & 9663 & 100 \\
\hline
\end{tabular}


Analysis of indicators in Table 2 indicates an almost stable structure of the number of teleconsultations in the context of specialties for 5 years. The table shows data only for 2016 and the last analyzed year. The evaluation of the indicators revealed the main specialties that are in demand among patients. These are hematology $(29 \%-24 \%)$, endocrinology $(14.3 \%-19.2 \%)$ and neurology $(7 \%-8 \%)$. The high level of consultations on hematology issues is noteworthy, the percentage is about $30 \%$ of all teleconsultations conducted. This is primarily due to the high level of curation of patients with this pathology, which is associated with the difficulty in establishing a diagnosis and choosing therapeutic and diagnostic tools for treatment and prevention. In addition, hematology is often associated with oncology, so the therapeutic service directs the patient to a consultation in order to reduce the cases of ignoring the symptoms of such complex nosological forms of diseases. Another factor that affects the high level of demand in this type of consultation is the low level of the number of specialists in this profile, which can be simply counted on your fingers. At the same time, it is necessary to note the concentration of highly qualified specialists in this field in $\mathrm{RCH}$ No. 1. A large number of teleconsultations in endocrinology can be explained by a sharp increase in the incidence of diabetes mellitus among the population in all gender and age groups. A fairly high need for teleconsultations in neurology can be similarly explained, which is also associated with an increase in the number of neurological diseases, including strokes.

\section{Conclusions}

It is obvious that the use of telemedicine technologies, including tele-consultations, allows:

- to reduce the number of possible complications of the treatment and diagnostic process, as well as to increase the level of detected diseases in the early stages;

- to increase the focus on the proactive detection of pathological conditions, thereby increasing the preventive orientation in the treatment and diagnostic process of many nosological forms of diseases;

- increase social and economic efficiency both in the activities of the medical organization and from the perspective of an individual patient;

- to increase the availability and quality of medical care, especially for patients living in remote areas, thereby improving the level and quality of life of the population;

- to create statistical client databases that help monitor and track changes in the health status of the population, including when using electronic mobile applications;

- highly qualified specialists of leading foreign and domestic clinics to exchange experience, information and analytical material on various issues, which can partially solve the problem of staff shortages of medical organizations in remote and sparsely populated areas;

- to conduct continuous training not only for medical personnel, but also for patients and the population, which is very important in today's unpredictable conditions of society development;

- to accumulate, store and process information and analytical material on the dynamics of the health status of the population.

At the same time, it is necessary to note some shortcomings that will have to be overcome in the near future. Today, not all medical professionals are ready to implement telecommunication technologies in the practice of a medical organization, due to the lack of knowledge, skills and experience working with information technologies, especially in groups of specialists of older age groups. Thus, in our opinion, it is necessary to conduct additional educational work in the field of using modern information and telecommunications technologies, as well as mobile applications of electronic health. In 
addition, it is necessary to increase the level of knowledge and competencies in the field of information technology not only for medical specialists, but also to increase and improve the quality of training of mathematical and engineering specialists working in the field of medicine and healthcare.

The authors express their gratitude to Elena Borisovna Almazova, the head of the Statistics Department of the State Budgetary Health Care Institution of the Sverdlovsk Region "SRCH No. 1" in Yekaterinburg, for her help in generating statistical information on the number of teleconsultations conducted.

\section{References}

1. Report on the second global survey on eHealth Global Observatory for eHealth series, 2 (2010) http://zdrav.expert/

2. A. A. Akhmed, M. A. Blinnikov, R. Ya. Pirmagomedov, R. I. Glushakov, A. E. Kucheryavyy, Information technology and telecommunications, 3 (2017)

3. E. L. Boyko, Bulletin of Roszdravnadzor, 1 (2017)

4. O. E. Karpov, G. S. Klimenko, G. S. Lebedev, Modern high technologies, 7(1), 38 (2016)

5. A.V. Vladzimirsky, LAP Lambert Academic Publishing, 407 (2014)

6. AMA Adopts Principles to Promote Safe, Effective mHealth Applications (2016) https://www.ama-assn.org/

7. R. E. Glasgow, E. B. Fisher, D. Haire-Joshu, M. G. Goldstein, Am J Public Health (2007)

8. Guide to Gerontology and Geriatrics. Fundamentals of Gerontology. General geriatrics, ed. V.N. Yarygina, A.S. Melent'eva, 1, 367 (2010)

9. MHealth market in Russia and worldwide, results of 2014 - Research by J'son \& Partners, http://json.tv/

10. Guide to Gerontology and Geriatrics. Fundamentals of Gerontology. General geriatrics, ed. V.N. Yarygina, A.S. Melent'eva, 1, 367 (2010)

11. Y. Yu. Kubrick, Doctor and information technologies, 1 (2017)

12. A.A. Oshkordina, N.N. Kiveleva, N.V. Bryksina, Competitiveness in the global world: economics, science, technology, 8-5(55), 76 (2017) 